\title{
HARRY BATEMAN \\ 1882-1946
}

Harry Bateman was born in Manchester, England, May 29, 1882. He was the third and youngest child of Samuel and Marnie Elizabeth (Bond) Bateman. His father, who was born in Congleton, Cheshire, was a druggist and commercial traveler. His mother was born in New York City in 1853 (her father, who came from Lancaster, having been a planter in the West Indies and America). He lived from 1884 to 1890 in Oldham, Lancashire, and his early education was received at home since, as he records, his mother did not wish him to acquire the Lancashire accent. He recounts two incidents of these early years in a manner which conveys some impression of the quiet, dry humor which was characteristic of him in later life. In order not to spoil this impression we use his own words: "One day a Mr. Pullinger, to whom my father had been apprenticed, was visiting us. As a result of some questions he had put to me he recommended me to study mathematics. I was quite impressed but my memory played me a trick when a lady asked me a few days later what I was going to study. My reply was that I was going to study acrobatics. She then asked me where I was going to perform and I was at a loss for an answer. Since I have learned recently that Dr. Thomas Young was an expert tight rope walker and harlequin my mistake does not seem so bad after all." The second story of his early days runs as follows: "Perhaps my love for the exact sciences dates from the day when I went with my sister to the home of one of her girl friends. The father of this girl was very stout and when I met him I gazed at him in astonishment and finally spoke thus: 'Mr. Booth, the next time I come to see you I am going to bring with me mother's inch tape and measure you. I think your waist line is about two yards. ' No, Harry,' replied the good humoured Mr. Booth, 'it's nearly three'." From 1891 to 1900 he attended Board School and Grammar School in Manchester. He held Manchester City Council and Langworthy Scholarships at the Grammar School where he specialized in mathematics and ended by winning a Derby Scholarship and sizarship at Trinity College, Cambridge. When he was at Board School, and not yet twelve years old, a teacher named Arthur Gronowsky offered a prize of one shilling to the boy who was first able to demonstrate the first twelve propositions in the first book of Euclid. A shilling seemed a lot in those days to young Bateman, and he set to work to win the prize. They had good teachers then in Manchester (and, doubtless, still have) and this small piece of bread 
cast on the waters by one of them certainly brought returns.

At Trinity College Bateman won a major scholarship in 1902 and took his B.A. in 1903, being bracketed Senior Wrangler with P. E. Marrack. He was Smith's Prizeman and won a fellowship in 1905 and took his M.A. in 1906. He worked very hard during his last year (1904-1905) at Cambridge for in addition to his dissertations for the Smith's Prize and fellowship, he marked papers for the Briggs Correspondence School and coached for the Mathematical Tripos. After winning his fellowship he studied for a year on the continent, visiting Göttingen and Paris. In 1906 he was appointed Lecturer in Mathematics at Liverpool University. Before taking up this appointment he visited Professor Carey who was head of the department of mathematics at Liverpool, and he recounts that Carey's boys "besieged me with questions." At night one of them said to his father, "You told us that Mr. Batemen was a Senior Angler but he doesn't seem to know anything about fishing."

After one year at Liverpool Bateman was appointed Reader in Mathematical Physics at Manchester University. In 1910 he was appointed Lecturer in Mathematics at Bryn Mawr College where Charlotte Angas Scott, another English mathematician, was head of the department of mathematics. He spent only two years at Bryn Mawr and we can only surmise that he was not particularly successful as a teacher of young ladies or that he did not find the work particularly congenial. In 1912 he received an appointment as Johnston Scholar at Johns Hopkins University where Frank Morley, an old Cambridge mathematician, was head of the department of mathematics. The Johnston Scholarship in those days at Hopkins was a research scholarship, and the holder could give a seminar if he felt like doing so and if there were any students who felt like taking the course. Bateman had married in the summer of 1912 Ethel Horner Dodd and a son was born in 1914. The death of this son in 1917 was a blow which left its mark but which was borne with a courage which revealed the inner strength of the man. The Batemans later adopted a daughter Joan, who prepared the list of publications at the end of this memoir.

Bateman spent five years at Hopkins, holding the Johnston Scholarship for three years and being Lecturer in Mathematics for the two year period 1915-1917. In order to add to the small income from his scholarship and, later, his lectureship, he taught at the Bureau of Standards and at Mount Saint Agnes College and reviewed papers for the Weather Bureau; he also spent the summer of 1915 in Washington working for the Department of Terrestrial Magnetism. 
In 1917 he was appointed Professor of Mathematics, Theoretical Physics and Aeronautics at Throop College (now the California Institute of Technology), Pasadena, California. He held this position until his sudden death from coronary thrombosis on January 21, 1946 , while on the train to New York to receive an award from the Institute of Aeronautical Sciences.

Bateman's distinction as a mathematical physicist was widely recognized. He was a Fellow of the Royal Society (1928), a member of the National Academy of Sciences (1930) and of the American Philosophical Society (1924). He was vice president of the American Mathematical Society (1935) and Gibbs' Lecturer of the Society (1943). The last years of his life were devoted mainly to work connected with the war; he was a member of the War Preparedness Committee of the American Mathematical Society and chief consultant in aeronautics for the American Mathematical Society and the Mathematical Association of America.

The writer of this memoir was first brought into contact with Harry Bateman under the following circumstances. In 1914 I was awarded a Traveling Studentship in Mathematical Physics by the National University of Ireland and was looking about for some place to study. My professor, A. W. Conway, told me that there was a young man, Bateman, at Hopkins and that he thought that I could not do better than study with him. I followed this advice and, looking back over a third of a century, I judge the advice to have been sound. Bateman, a frail slight man of 32 , was lecturing on The Absolute Calculus and Electrodynamics (remember that this was 1914 and that four years or more had to elapse before most of us in this country heard of Einstein's General Theory of Relativity). As I recall the situation, six students started the course and by March I was, if my memory is correct, the only student. I do not think that this diminution of the size of his class bothered the lecturer very much, and I have sometimes thought that if the vicissitudes of student life had prevented my attendance, the lecture would have been none-the-less delivered. By common standards he was not (in those early days) a good lecturer. He was too detached, too objective and perhaps too scornful of histrionic effects, and we were too untrained to profit as much as we should have from the instruction he gave us. As time went on the scene changed and he must have changed with it for I have heard enthusiastic reports of his lectures from students who took courses under him in the late twenties and thirties at the California Institute of Technology. As I think back over my two years of association (1914-1916) with him I remember well a feeling 
of amazement, mingled with discouragement, which came over me when I discovered the thoroughness of the man. He already possessed a large, carefully indexed card-catalogue on each card of which was written in his minute, but beautifully clear, handwriting an abstract of a paper which he had read. I am told that in later years this cardcatalogue crowded him out of his office and almost out of his home. No wonder, then, that his books and papers bristle with references which are a veritable mine of useful source material. His memory was phenomenal. No matter what stubborn integral or intractable differential equation you showed him, a moment's thought and a reference to the card catalogue never failed to produce something useful. General theories did not seem to have for him the same attraction as the special instance; the only exception to this was his devotion, which marked him as a true disciple of Hamilton, to the variational principle. As a master of the special instance I have not met his equal, nor one who approached him, and I do not think that we shall see his like again.

Bateman's best work centered around the development of the properties of special functions and the solution of the equations of Mathematical Physics. His first book, Mathematical analysis of electrical and optical wave motion, is unique and characteristic of the man. Into less than 160 small pages is crowded a wealth of information which would take an expert years to digest. Some of the material in this book may be found in expanded form in his monumental work, Partial differential equations of mathematical physics, published by the Cambridge University Press in 1932 and republished with minor additions by the Dover Press in 1944. This book has already taken its place beside Lamb's Hydrodynamics and Love's Elasticity as one of the classics which are part of the equipment of every worker in applied mathematics. Amongst the many results involving the functions of special importance in mathematical physics which are due to Bateman we select for special mention the formula

$$
\int_{0}^{z} J_{\mu}(t) J_{\nu}(z-t) \frac{d t}{t}=\frac{J_{\mu+\nu}(z)}{t}, \quad R(\mu)>0, R(\nu)>-1
$$

$(J(t)$ being the familiar Bessel function of the first kind). This result is treated fully in Watson's book on Bessel functions and has been discussed by L. J. Mordell (J. London Math. Soc. vol. 5, pp. 203-208).

In the early years of the present century, when Bateman was a student at Cambridge, the theory of integral equations dominated the mathematical scene. Fredholm's epoch making paper (Acta Math., vol. 27) appeared in 1903 and Hilbert was actively developing the 
subject at Göttingen when Bateman visited there in 1906. It was natural, then, that this new field of mathematical research should have occupied the attention of the young analyst. Papers 15, 19, 21, $22,25,26,27,28$ and 42 of the bibliography below contain substantial contributions to the subject and the Report (1) to the British Association for the Advancement of Science is a valuable account of the theory as it stood in 1910. In the paper (39) Bateman applied (independently of Herglotz, who had the same idea) integral equation theory to the propagation of earthquake waves through the interior of the earth. He showed how to determine, from a knowledge of the time taken by an earthquake wave to reach various points on the surface of the earth, the velocity of propagation of the wave at various points in the interior of the earth. The full importance of this result has not yet, in our opinion, been sufficiently exploited. The velocity of propagation tells us the ratio of the appropriate elastic constant to the density. If we know this for both types of waves, longitudinal and transverse, we can determine how the density varies with the pressure. Knowing this we can set up differential equations whose solutions tell us the density and pressure throughout the interior of the earth as functions of the distance from the center. It should then be possible, from a knowledge of the variation of compressibility with temperature, to estimate the variation of temperature throughout the earth's interior.

The field in which Bateman stood preeminent was that of electrodynamics. In 1908 Hargreaves published in volume 21 of the Transactions of the Cambridge Philosophical Society a paper in which he showed that Maxwell's differential equations were merely the expression in differential or local form of relations between integrals over two-dimensional and three-dimensional spreads in four-dimensional space-time. Every electrical engineer knows that the relation $\operatorname{div} \boldsymbol{B}=0$ ( $\boldsymbol{B}=$ magnetic induction $)$ is merely the differential, or local, form of statement of the fact that, in magnetostatics, the flux of magnetic induction through any closed surface is zero. This integral or global statement is much closer to the physics of the matter than the local statement $\operatorname{div} B=0$. For non-static phenomena Maxwell's equations

$$
-\frac{d B}{d t}=c \operatorname{curl} E ; \quad \operatorname{div} B=0
$$

are merely the local form of the global statement that the flux of the magnetic induction-electric intensity tensor across any closed twodimensional spread in four-dimensional space is zero. In the paper 
(50) Bateman exploited fully this idea and showed that the group of transformations under which Maxwell's electrodynamic equations are invariant is the group of conformal transformations of fourdimensional space-time. The fundamental significance of this paper from the point of view of relativity theory was not generally recognized but Klein, in his Vorlesungen über die Entwicklung der Mathematik im 19. Jahrhundert, vol. 2, 1927, directs attention to this significant and pioneer work of Bateman.

This brings us to the end of the first stage of Bateman's career. In 1912 he was thirty years old, had published some 64 papers and had been two years in America. He was preparing to accept Morley's offer of a Johnston Scholarship at Hopkins (roughly equivalent to a National Research Council fellowship of today). As we look back on the situation we cannot escape the inevitable Why? Here was a man of international reputation, pleasant (if self-effacing) personality, and he had to spend the next five years in a position designed for a young unmarried Ph.D. of promise or for an established scholar on leave-of-absence or sabbatical leave. When we think of the "odd-jobs" he had to do to eke out a subsistence, the reading of papers for the Weather Bureau, the hot Washington summer at the Bureau of Standards, the teaching at Mount Saint Agnes and then recall that during this period he wrote his book on electrical and optical wavemotion, we can only subscribe to the old Latin tag: Per aspera ad astra.

The influence of Morley upon Bateman is shown by the publication of several papers on geometrical topics (66), (67), (68), (72). His main work, however, during the Hopkins period (1912-1917) dealt with electromagnetic theory. He was particularly interested in the lines of electric force due to a moving electron and (following J. J. Thomson) in the connection between these and the structure of the aether. During this period he wrote his book on differential equations. While this book has not generally been found well adapted to beginning courses in the subject, it well repays study, particularly by those who are more interested in the applications of differential equations to mathematical physics than in the applications to differential geometry and the theory of functions.

Shortly after his appointment in 1917 to the chair of Mathematics, Theoretical Physics and Aeronautics at Throop College (now the California Institute of Technology) Bateman published his first paper (94) on hydrodynamics, a subject which was to engage a large share of his attention during the last years of his life. However, most of his papers published during the decade 1918-1928 deal with electro- 
magnetic theory. During this period his monograph on electromagnetism appeared as Bulletin No. 4 of the National Research Council (1922). In addition to his papers on electromagnetism he published a paper (97) containing an interesting application of integral equation theory to mathematical economics, two papers (106) and (119) on the numerical solution of integral equations, several papers (100), (104), (114), (116) on potential theory, papers (98), (133) and (134) on elasticity, and a paper (128) on geometry.

In 1925 Bateman was appointed a member of a committee on hydrodynamics of the National Research Council and was assigned the problem of writing those sections af a report on hydrodynamics which dealt with viscous fluids and compressible flow. The report appeared in 1932 as Bulletin No. 84 of the National Research Council. It is a large report of some 634 pages and of these Bateman's part ran to over 500 pages and is a veritable mine of information and of references to all papers of significance prior to 1932 . The section on compressible fluids has been widely used and the report has been for several years out of print. Paper (136) is an important contribution to the theory of two-dimensional compressible fluid flow. The work done by Bateman on this subject during the last five years of his life is not yet available to the public due to secrecy imposed by war conditions.

Bateman was always interested in the problem of numerical computation. In collaboration with A. A. Bennett and W. E. Milne he wrote a report on the numerical integration of differential equations which was published in 1933 as Bulletin No. 92 of the National Research Council. In 1944 he published, in collaboration with R. C. Archibald, a Guide to tables of Bessel functions which appeared in the first volume of the journal: Mathematical Tables and other Aids to Computation.

His Gibbs Lecture, The control of an elastic fluid, appeared in the Bulletin of the American Mathematical Society, vol. 51 (1945) and in the same year articles by him on dynamics and elasticity appeared in the Encyclopaedia Britannica. His last paper, appropriately entitled Some integral equations of potential theory, appeared after his death in the Journal of Applied Physics vol. 17 (1946). We learn from a note by Professor E. T. Bell in the Quarterly of Applied Mathematics vol. 4 (1946) that he was engaged, in the time he could snatch from his war work, on "what he regarded as his most useful contributions to mathematical scholarship: an exhaustive work on definite integrals, and a critical census of all the special functions that have been considered in mathematics." It is pleasant to know that the California 
Institute of Technology has invited Professor Erdélyi to prepare these works for publication.

This notice fails to convey an adequate impression of the personality of the great scientist and scholar who was lost to the world in the passing of Harry Bateman. Modest, reserved, cultured and selfeffacing he was, in its true sense, a gentle man. He was very English and he must have long looked back over his shoulder, before becoming, in 1927, a citizen of the new exuberant country in which he spent more than half his life, to the quiet England of Victoria and Edward VII. He was an expert chess player and participated, when eighteen years of age, in a chess tournament between England and America. We profit from his labors and are the better for his having lived amongst us.

\section{BiBLIOGRAPHY}

\section{Books}

1. The mathematical analysis of electrical and optical wave motion on the basis of Maxwell's equations, Cambridge University Press, 1915, 6+159 pp.

2. Differential equations, Longmans, Green \& Co., London, 1918, $11+306$ pp.

3. Partial differential equations of mathematical physics, Cambridge University Press, 1932, $22+522$ pp.; Dover Publications, 1944, $21+522$ pp.

\section{REPORTS}

1. Report on the history and present state of the theory of integral equations, British Association for the Advancement of Science vol. 80 (1910) pp. 345-424.

2. Equations for the description of electromagnetic phenomena, Bulletin of the National Research Council, no. 4, 1922, pp. 96-161.

3. Hydrodynamics, Bulletin of the National Research Council, No. 84, 1932, pp. 89-579, 590-601.

4. Numerical integration of differential equations, Bulletin of the National Research Council, no. 92, 1933, pp. 1-108.

\section{Articles}

Dynamics, elasticity, Encyclopaedia Britannica, 1945.

\section{PAPERS}

1. Question 14943, Educational Times (2) vol. 1 (1902) pp. 98-100.

2. Question 15119, Educational Times (2) vol. 3 (1903) pp. 110-111.

3. Question 15221, Educational Times (2) vol. 4 (1903) p. 88.

4. The determination of curves satisfying given conditions, Proc. Cambridge Philos. Soc. vol. 12 (1903) pp. 163-171.

5. Question 15440, Educational Times (2) vol. 5 (1904) p. 68.

6. Question 15388, Educational Times (2) vol. 5 (1904) pp. 105-106.

7. The solution of partial differential equations by means of definite integrals, Proc. London Math. Soc. (2) vol. 1 (1904) pp. 451-458.

8. Certain definite integrals and expansions connected with the Legendre and Bessel 
functions, Messenger of Mathematics (2) vol. 33 (1904) pp. 182-188.

9. A generalization of the Legendre polynomial, Proc. London Math. Soc. (2) vol. 3 (1905) pp. 111-123. 238.

10. The Weddle quartic surface, Proc. London Math. Soc. (2) vol. 3 (1905) pp. 225-

11. The correspondence of Brook Taylor, Bibliotheca Mathematica (3) vol. 7 (1906) pp. 367-371.

12. Note on the solution of linear differential equations by means of definite integrals, Messenger of Mathematics (2) vol. 35 (1906) pp. 140-141. 90-115.

13. The theory of integral equations, Proc. London Math. Soc. (2) vol. 4 (1906) pp.

14. On the inversion of a definite integral, Proc. London Math. Soc. (2) vol. 4 (1906) pp. 461-498.

15. Sur l'équation de Fredholm, Bull. Sci. Math. (2) vol. 30 (1906) pp. 264-270.

16. A class of integral equations, Trans. Cambridge Philos. Soc. vol. 20 (1906) pp. 233-252.

17. A type of hyperelliptic curve and the transformations connected with it, Quart. J. Math. vol. 37 (1906) pp. 277-286.

18. On an expansion of an arbitrary function in a series of Bessel functions, Messenger of Mathematics (2) vol. 36 (1906) pp. 31-37.

19. On definite functions, Messenger of Mathematics (2) vol. 37 (1907) pp. 91-95.

20. The inversion of a definite integral, Math. Ann. vol. 63 (1907) pp. 525-548.

21. The application of integral equations to the determination of expansions in series of oscillating functions, Trans. Cambridge Philos. Soc. vol. 20 (1907) pp. 281-290.

22. The reality of the roots of certain transcendental equations occurring in the theory of integral equations, Trans. Cambridge Philos. Soc. vol. 20 (1907) pp. 371-382.

23. (H. B. and D. M. Y. Sommerville). Question 16009, Educational Times (2) vol. 11 (1907) pp. 57-61.

24. Some geometrical theorems occurring in hydrostatics, Messenger of Mathematics vol. 37 (1907) pp. 119-123.

25. A formula for the solving function of a certain integral equation of the second kind, Messenger of Mathematics (2) vol. 37 (1908) pp. 179-187.

26. Notes on integral equations. I. The integral equation of the first kind, Messenger of Mathematics (2) vol. 38 (1908) pp. 8-13.

27. Notes on integral equations. II. The method of least squares, Messenger of Mathematics (2) vol. 38 (1908) pp. 70-76.

28. On the application of integral equations to the determination of upper and lower limits to the value of a double integral, Trans. Cambridge Philos. Soc. vol. 21 (1908) pp. 123-128.

29. On essentially positive double integrals and the part which they play in the theory of integral equations, British Association Reports (Leicester) vol. 77 (1908) pp. 447449.

30. Question 16090, Educational Times (2) vol. 13 (1908) pp. 72-74, 91.

31. The tangent plane which can be drawn to an algebraic surface from a multiple line, Archiv der Mathematik und Physik (3) vol. 13 (1908) pp. 48-51.

32. A method of calculating the number of degrees of freedom of a molecule among which the partition of energy is governed by the principal temperature, Memoirs and Proceedings of the Manchester Literary and Philosophical Society vol. 53 (1908) pp. 1-9.

33. The solution of linear differential equations by means of definite integrals, Trans. Cambridge Philos. Soc. vol. 21 (1909) pp. 171-196. 
34. Notes on integral equations. III. The homogeneous integral equation of the first kind, Messenger of Mathematics (2) vol. 39 (1909) pp. 6-19.

35. The conformal transformations of a space of four dimensions and their applications to geometric optics, Proc. London Math. Soc. (2) vol. 7 (1909) pp. 70-89; British Association Reports (Dublin) vol. 78 (1909) pp. 627-629.

36. The reflexion of light at an ideal plane mirror moving with a uniform velocity of translation, Philosophical Magazine (6) vol. 18 (1909) pp. 890-895.

37. The solution of a system of differential equations occurring in the theory of radioactive transformations, Proc. Cambridge Philos. Soc. vol. 15 (1910) pp. 423-427.

38. The linear difference equation of the third order and a generalisation of a continued fraction, Quart. J. Math. vol. 41 (1910) pp. 302-308.

39. The solution of the integral equation connecting the velocity of propagation of an earthquake-wave in the interior of the earth with the times which the disturbance takes to travel to the different stations on the earth's surface, Philosophical Magazine (6) vol. 19 (1910) pp. 576-587; Physikalische Zeitschrift vol. 11 (1910) pp. 96-99.

40. Notes on integral equations. IV. The expansion theorems and the integral equation of the first kind, Messenger of Mathematics (2) vol. 39 (1910) pp. 129-135.

41. Notes on integral equations. V. Integral equations with variable limits, Messenger of Mathematics (2) vol. 39 (1910) pp. 173-178.

42. Notes on integral equations. VI. The homogeneous integral equation of the first kind, Messenger of Mathematics (2) vol. 39 (1910) pp. 182-191.

43. The determination of solutions of the equation of wave motion involving an arbitrary function of three variables which satisfies a partial differential equation, Trans. Cambridge Philos. Soc. vol. 21 (1910) pp. 257-280.

44. Question 16215, Educational Times (2) vol. 18 (1910) pp. 86-87.

45. A system of circles derived from a cubic space curve and the properties of a certain configuration of fifteen lines, Messenger of Mathematics (2) vol. 40 (1910) pp. 8187.

46. Kummer's quartic surface as a wave surface, Proc. London Math. Soc. (2) vol. 8 (1910) pp. 375-382.

47. The physical aspect of time, Memoirs and Proceedings of the Manchester Literary and Philosophical Society vol. 54 (1910) 13 pp.

48. Correction to Mr. H. Bateman's paper on the reflexion of light at an ideal plane mirror moving with uniform velocity of translation, Philosophical Magazine (6) vol. 19 (1910) p. 824.

49. Elementare elektronensysteme (Elementary systems of electrons), Physikalische Zeitschrift vol. 11 (1910) pp. 318-320.

50. The transformation of the electrodynamical equations, Proc. London Math. Soc. (2) vol. 8 (1910) pp: 223-264.

51. The transformation of coordinates which can be used to transform one physical problem into another, Proc. London Math. Soc. (2) vol. 8 (1910) pp. 469-488.

52. The relation between electromagnetism and geometry, Philosophical Magazine (6) vol. 20 (1910) pp. 623-628.

53. On the probability distribution of $\alpha$-particles, Philosophical Magazine (6) vol. 20 (1910) pp. 704-707.

54. Notes on integral equations. VII. The solution of partial differential equations by means of definite integrals, Messenger of Mathematics (2) vol. 41 (1911) pp. 94-101.

55. The foci of a circle in space and some geometrical theorems connected therewith

British Association Reports (Sheffield) vol. 80 (1911) pp. 532-533

56. Some problems in the theory of probability, Philosophical Magazine (6) vol. 21 (1911) pp. 745-752. 
57. The transformation of a particular type of electromagnetic field and its physical interpretation, Proc. London Math. Soc. (2) vol. 10 (1911) pp. 7-14.

58. On certain vectors associated with an electromagnetic field and the reflection of a disturbance at the surface of a perfect conductor, Proc. London Math. Soc. (2) vol. 10 (1911) pp. 96-115.

59. The fundamental equations of the theory of electrons and the infinitesimal transformation of an electromagnetic field into itself, Bull. Amer. Math. Soc. vol. 17 (1911) p. 525.

60. On a set of kernels whose determinants form a Sturmian sequence, Bull. Amer. Math. Soc. vol. 18 (1912) pp. 179-182.

61. Notes on integral equations. VIII. Some simple definite integrals derived from the formulae of Fourier and Abel, Messenger of Mathematics (2) vol. 41 (1912) pp. 180184.

62. Some geometrical theorems connected with Laplace's equation and the equation of wave motion, Amer. J. Math. vol. 34 (1912) pp. 325-360.

63. A new type of solution of Laplace's equation, Ann. of Math. (2) vol. 14 (1912) pp. 51-56.

64. Some equations of mixed differences occurring in the theory of probability and the related expansions in series of Bessel's functions, Proceedings of the Fif th International Congress of Mathematicians, vol. 1, 1913, pp. 291-294.

65. Sonin's polynomials and their relation to other functions, Bull. Amer. Math. Soc. vol. 19 (1913) p. 394. 78.

66. The double tangents of a binodal quartic, Amer. J. Math. vol. 35 (1913) pp. 57-

67. The expression of the equation of the general quartic curve in the form $A / x x^{\prime}$ $+B / y y^{\prime}+C / z z^{\prime}=0$, Bull. Amer. Math. Soc. vol. 19 (1913) p. 19.

68. The degenerate cases of Hierholzer's octavic surface, Johns Hopkins University Circular vol. 7 (1913) pp. 42-46.

69. Corpuscular radiation, Philosophical Magazine (6) vol. 26 (1913) pp. 579-585.

70. A new type of solution of Maxwell's equations, Ann. of Math. (2) vol. 15 (1914) pp. 106-111.

71. A general result in the theory of partial differential equations, Messenger of Mathematics (2) vol. 43 (1914) pp. 164-171.

72. The quartic curve and its inscribed configurations, Amer. J. Math. vol. 36 (1914) pp. 357-386.

73. The classification of electromagnetic fields, Philosophical Magazine (6) vol. 27 (1914) pp. 136-147.

74. Some recent researches on the motion of fluids, Monthly Weather Review vol. 43 (1915) pp. 163-170.

75. On a porism connected with the theory of Maxwell's equations and a method of obtaining the lines of electric force due to a moving point charge, Amer. J. Math. vol. 37 (1915) pp. 192-194.

76. On systems of partial differential equations and the transformation of spherical harmonics, Proceedings of the Edinburgh Royal Society vol. 36 (1915) pp. 300-312.

77. On certain solutions of Maxwell's equations, Messenger of Mathematics (2) vol. 45 (1915) pp. 1-11.

78. Time and electromagnetism, Messenger of Mathematics (2) vol. 45 (1915) pp. 97-115. 309.

79. The structure of the aether, Bull. Amer. Math. Soc. vol. 21 (1915) pp. 299-

80. On multiple electromagnetic fields, Bull. Amer. Math. Soc. vol. 22 (1916) p. 377. 
81. A certain system of linear partial differential equations, Bull. Amer. Math. Soc. vol. 22 (1916) pp. 329-335.

82. On the relation of the theory of integral equations to the subject of the calculus of operations and functions, Science Progress vol. 11 (1917) pp. 508-512.

83. Some fundamental concepts of electrical theory, Philosophical Magazine (6) vol. 34 (1917) pp. 405-423.

84. On the motion of continuous distributions of electricity, Messenger of Mathematics (2) vol. 46 (1917) pp. 136-145.

85. Doppler's principle for a windy atmosphere, Monthly Weather Review vol. 45 (1917) pp. 441-442.

86. Some differential equations occurring in the electrical theory of radiation, Messenger of Mathematics (2) vol. 47 (1918) pp. 161-173.

87. On a solution of the wave-equation, Tôhoku Math. J. vol. 13 (1918) pp. 205-209.

88. The electromagnetic vectors, Physical Review (2) vol. 12 (1918) pp. 459-481.

89. Mathematical theory of sound ranging, Monthly Weather Review vol. 46 (1918) pp. 4-11.

90. The structure of an electromagnetic field, Proc. Nat. Acad. Sci. U. S. A. vol. 4 (1918) pp. 140-145.

91. The solution of the wave equation by means of definite integrals, Bull. Amer. Math. Soc. vol. 24 (1918) pp. 296-301.

92. The nature of a moving electric charge and its lines of electric force, Proc. London Math. Soc. (2) vol. 18 (1919) pp. 95-135.

93. On general relativity, Philosophical Magazine (6) vol. 37 (1919) pp. 219-223.

94. Rotating cylinders and rectilinear vortices, Bull. Amer. Math. Soc. vol. 25 (1919) pp. 358-374.

95. Radiation from a moving magneton, Proc. Nat. Acad. Sci. U.S. A. vol. 5 (1919) pp. 367-371; Messenger of Mathematics (2) vol. 48 (1919) pp. 56-76.

96. On a differential equation occurring in Page's theory of electromagnetism, Proc. Nat. Acad. Sci. U. S. A. vol. 6 (1920) pp. 528-529.

97. An integral equation occurring in a mathematical theory of retail trade, Messenger of Mathematics (2) vol. 49 (1920) pp. 134-137.

98. A differential equation occurring in the theory of the propagation of waves, Messenger of Mathematics (2) vol. 50 (1920) pp. 95-101.

99. Notes on electrical theory, Bull. Amer. Math. Soc. vol. 27 (1921) pp. 217-225.

100. Correspondences between three-dimensional and four-dimensional potential problems, Messenger of Mathematics (2) vol. 51 (1921) pp. 151-160.

101. Electricity and gravitation, Physical Review (2) vol. 17 (1921) pp. 64-69.

102. An electromagnetic theory of radiation, Philosophical Magazine (6) vol. 41 (1921) pp. 107-113.

103. On lines of electric induction and the conformal transformations of a space of four dimensions, Proc. London Math. Soc. (2) vol. 21 (1922) pp. 256-270.

104. Some problems in potential theory, Messenger of Mathematics (2) vol. 52 (1922) pp. 71-78.

105. The stress-energy tensor in electromagnetic theory and a new law of force, Physical Review (2) vol. 20 (1922) pp. 243-248.

106. On the numerical solution of linear integral equations, Proc. Roy. Soc. London Ser. A vol. 100 (1922) pp. 441-449.

107. Electromagnetism and dynamics, Messenger of Mathematics (2) vol. 52 (1922) pp. 116-128.

108. On the conformal transformations of a space of four dimensions and lines of electric force, Proc. London Math. Soc. (2) vol. 20 (1922) pp. v-vi. 
109. Electron in uniform motion, Science vol. 57 (1923) pp. 238-240.

110. On the radiation of electric dipoles, Proc. London Math. Soc. Records, November, 1923.

111. An electromagnetic theory of light-darts, Bull. Amer. Math. Soc. vol. 29 (1923) pp. 385-393.

112. On the theory of light-quanta, Philosophical Magazine (6) vol. 46 (1923) pp. 977-991.

113. (H. B. and P. Ehrenfest). The derivation of electromagnetic fields from a basic wave-function, Proc. Nat. Acad. Sci. U.S.A. vol. 10 (1924) pp. 369-374.

114. Derivation of three-dimensional potentials from four-dimensional potentials, Bull. Amer. Math. Soc. vol. 30 (1924) p. 15.

115. The form of an isolated electric particle, Messenger of Mathematics (2) vol. 53 (1924) pp. 145-152.

116. On some solutions of Laplace's equation, Messenger of Mathematics (2) vol. 54 (1924) pp. 28-32.

117. The field of an electron at rest and in uniform motion, Philosophical Magazine (6) vol. 49 (1925) pp. 1-18.

118. An extension of Lagrange's expansion, Bull. Amer. Math. Soc. vol. 31 (1925) p. 386; Trans. Amer. Math. Soc. vol. 28 (1926) pp. 346-356.

119. Numerical solution of an integral equation, Bull. Amer. Math. Soc. vol. 31 (1925) p. 111.

120. On the occasional need of very accurate logarithms, Amer. Math. Monthly vol. 32 (1925) p. 249.

121. The stability of electrons and protons, Messenger of Mathematics (2) vol. 54 (1925) pp. 142-149.

122. Theory of the condenser in a new electrostatics, Philosophical Magazine (6) vol. 49 (1925) pp. 1-22.

123. Local electromagnetic fields, Proceedings of the Edinburgh Mathematical Society, vol. 44 (1926) pp. 85-89.

124. Algebraic and transcendental equations connected with the form of stream lines, Amer. J. Math. vol. 48 (1926) pp. 277-297.

125. A possible connection between the wave-theory of matter and electromagnetism, Nature vol. 118 (1926) pp. 839-840.

126. An expression for the energy in a new electrostatics, Messenger of Mathematics (2) vol. 55 (1926) pp. 161-168.

127. The radiation of energy and angular momentum, Physical Review (2) vol. 27 (1926) pp. 606-617.

128. A cubic curve connected with two triangles, Bull. Amer. Math. Soc. vol. 33 (1927) pp. 45-50.

129. Lagrangian functions and Schroedinger's rule, Proc. Nat. Acad. Sci. U.S.A. vol. 13 (1927) pp. 326-330. $55-60$.

130. A modification of Gordon's equations, Physical Review (2) vol. 30 (1927) pp.

131. The symmetry of the stress-tensor obtained by Schroedinger's rule, Proc. Nat. Acad. Sci. U.S.A. vol. 13 (1927) pp. 771-774.

132. Some remarks on the wave-theory of matter, Messenger of Mathematics (2) vol. 57 (1927) pp. 7-12.

133. The equation for the transverse vibrations of thin rods, Messenger of Mathematics (2) vol. 57 (1928) pp. 145-154.

134. Transverse seismic waves on the surface of a semi-infinite solid composed of heterogeneous materials, Bull. Amer. Math. Soc. vol. 34 (1928) pp. 343-348. 
135. Interpolation for airfoils, Messenger of Mathematics (2) vol. 57 (1928) pp. 187-192.

136. Notes on a differential equation which occurs in the two-dimensional motion of a compressible fluid and the associated variational problems, Proc, Roy. Soc. London Ser. A vol. 125 (1929) pp. 598-618.

137. Some properties of spherical harmonics, Bull. Amer. Math. Soc. vol. 36 (1930) pp. 306-314.

138. Variable flow in pipes, Physical Review (2) vol. 35 (1930) pp. 177-183.

139. Physical problems with discontinuous initial conditions, Proc. Nat. Acad. Sci. U.S.A. vol. 16 (1930) pp. 205-211. 162.

140. A solution of the wave-equation, Ann. of Math. (2) vol. 31 (1930) pp. 158-

141. Irrotational motion of a compressible inviscid fluid, Proc. Nat. Acad. Sci. U.S.A. vol. 16 (1930) pp. 816-825.

142. Solutions of a certain partial differential equation, Proc. Nat. Acad. Sci. U.S.A. vol. 17 (1931) pp. 562-567.

143. On dissipative systems and related variational principles, Physical Review (2) vol. 38 (1931) pp. 815-819. 1-8.

144. Lagrange's compound pendulum, Amer. Math. Monthly vol. 38 (1931) pp.

145. Sound rays as extremals, Journal of the Acoustical Society of America vol. 2 (1931) pp. 468-475.

146. Relations between confluent hypergeometric functions, Proc. Nat. Acad. Sci. U.S.A. vol. 17 (1931) pp. 689-690.

147. The $k$-function, a particular case of the confluent hypergeometric function, Trans. Amer. Math. Soc. vol. 33 (1931) pp. 817-831.

148. Some applications of Murphy's theorem, Bull. Amer. Math. Soc. vol. 39 (1933) pp. 118-123.

149. Logarithmic solutions of Bianchi's equation, Proc. Nat. Acad. Sci. U.S.A. vol. 19 (1933) pp. 852-854.

150. Variational principles in electromagnetism, Physical Review (2) vol. 43 (1933) pp. $481-484$.

151. Schroedinger's rule and hydrodynamics, Physical Review (2) vol. 43 (1933) pp. 363.

152. Some properties of a certain set of polynomials, Tôhoku Math J. vol. 37 (1933) pp. 23-38.

153. Functions orthogonal in the Hermitian sense. A new application of basic numbers, Proc. Nat. Acad. Sci. U.S.A. vol. 20 (1934) pp. 63-66.

154. Sidelights on electromagnetic theory, Physical Review (2) vol. 45 (1934) pp. 721-723.

155. The polynomial $F_{n}(x)$, Ann. of Math. (2) vol. 35 (1934) pp. 767-775.

156. Selective functions and operations, Amer. Math. Monthly vol. 41 (1934) pp. 556-562.

157. Operational equations, National Mathematics Magazine vol. 9 (1935) pp. 197-201.

158. (H. B. and S. O. Rice). Some expansions associated with Bessel functions, Proc. Nat. Acad. Sci. U.S.A. vol. 21 (1935) pp. 173-179.

159. A partial differential equation connected with the functions of the parabolic cylinder, Bull. Amer. Math. Soc. vol. 41 (1935) pp. 884-893.

160. Functional differential equations and inequalities, Proc. Nat. Acad. Sci. U.S.A. vol. 22 (1936) pp. 170-172. 
161. Two systems of polynomials for the solution of Laplace's integral equation, Duke Math. J. vol. 2 (1936) pp. 569-577.

162. Polynomials associated with those of Lerch, Monatshefte für Mathematik und Physik vol. 43 (1936) pp. 75-80.

163. Progressive waves of finite amplitude and some steady motions of an elastic fluid, Proc. Nat. Acad. Sci. U.S.A. vol. 22 (1936) pp. 607-619.

164. The polynomial $F_{n}(x)$ and its relation to other functions, Ann. of Math. (2) vol. 38 (1937) pp. 303-310.

165. Coulomb's function, Proc. Nat. Acad. Sci. U.S.A. vol. 24 (1938) pp. 321-325.

166. Rayleigh waves, Proc. Nat. Acad. Sci. U.S.A. vol. 24 (1938) pp. 315-320.

167. The lift and drag functions for an elastic fluid in two dimensional irrotational flow, Proc. Nat. Acad. Sci. U.S.A. vol. 24 (1938) pp. 246-251.

168. Halley's methods for solving equations, Amer. Math. Monthly vol. 45 (1938) pp. 11-17.

169. (H. B. and S. O. Rice). Integrals involving Legendre functions, Amer. J. Math. vol. 60 (1938) pp. 297-308.

170. Spheroidal and bipolar coordinates, Duke Math. J. vol. 4 (1938) pp. 39-50.

171. A partial differential equation associated with Poisson's work on the theory of sound, Amer. J. Math. vol. 60 (1938) pp. 293-296.

172. Paraboloidal coordinates, Philosophical Magazine (7) vol. 26 (1938) pp. $1063-$ 1068.

173. The transformation of a Lagrangian series into a Nezwtonian series, Proc. Nat. Acad. Sci. U.S.A. vol. 25 (1939) pp. 262-265.

174. The aerodynamics of reacting substances, Proc. Nat. Acad. Sci. U.S.A. vol. 25 (1939) pp. 388-391.

175. On some symmetrical potentials and the partial differential equation $V_{s s x x}$ $+V_{\text {seyy }}+V_{t t}=0$, Monatshefte für Mathematik und Physik vol. 48 (1939) pp. 322328.

176. The solution of harmonic equations by means of definite integrals, Bull. Amer. Math. Soc. vol. 46 (1940) pp. 538-542.

177. The polynomial of Mittag-Leffler, Proc. Nat. Acad. Sci. U.S.A. vol. 26 (1940) pp. $491-496$.

178. Some definite integrals occurring in aerodynamics, Applied Mechanics, Theodore von Kármán Anniversary Volume, California Institute of Technology, 1941, pp. 1-7.

179. The resistance of ships, National Mathematics Magazine vol. 16 (1941) pp. 79-88.

180. The form of a ship, National Mathematics Magazine vol. 16 (1941) pp. 141149.

181. An orthogonal property of the hypergeometric polynomial, Proc. Nat. Acad. Sci. U.S.A. vol. 28 (1942) pp. 374-377. 374.

182. Some asymptotic relations, Proc. Nat. Acad. Sci. U.S.A. vol. 28 (1942) pp. 371-

183. The influence of tidal theory upon the development of mathematics, National Mathematics Magazine vol. 18 (1943) pp. 14-26.

184. Some simple differential difference equations and the related functions, Bull. Amer. Math. Soc. vol. 49 (1943) pp. 494-512.

185. Note on the function $F(a, b ; c-n ; z)$, Proc. Nat. Acad. Sci. U.S.A. vol. 30 (1944) pp. 28-30.

186. The transformation of partial differential equations, Quarterly of Applied Mathematics vol. 1 (1944) pp. 281-296. 
187. (H. B. and R. C. Archibald). A guide to tables of Bessel functions, Mathematical Tables and Other Aids to Computation vol. 1 (1944) pp. 205-308.

188. Some integral relations, Bull. Amer. Math. Soc. vol. 50 (1944) pp. 745-749.

189. Hamilton's work in dynamics and its influence on modern thought, Scripta Mathematica vol. 10 (1944) pp. 51-63.

190. Two integral equations, Proc. Nat. Acad. Sci. U.S.A. vol. 31 (1945) pp. 196200.

191. The control of an elastic fluid, Bull. Amer. Math. Soc. vol. 51 (1945) pp. 601646.

192. The derivation of Euler's equations from a variational principle, Revista de Ciencias vol. 47 (1945) pp. 111-117.

193. (H. B. and C. L. Pekeris). Transmission of light from a point source in a medium bounded by diffusely reflecting parallel plane surfaces, Journal of the Optical Society of America vol. 35 (1945) pp. 651-657.

194. Some integral equations of potential theory, Journal of Applied Physics vol. 17 (1946) pp. 91-102.

F. D. MURNAGHAN 